\title{
SOCIAL MEDIA IMPLOSION: CONTEXT COLLAPSE!
}

\author{
Debra J. Borkovich, Robert Morris University, borkovich@rmu.edu \\ Jennifer Breese, Middle GA State University, jennifer.breese@mga.edu
}

\begin{abstract}
According to Facebook (2016), "context collapse," the decline of personal and original content sharing on its social media site, is on the rise. "Context collapse" refers to an infinitely possible online audience contrasted to the limited groups a person normally interacts with face-to-face. This paper explores the construct of "context collapse," its historical underpinnings, and its current influence and application to the implosion of social media. Through the interpretation of pre-existing literature and interviews with adult Facebook users, we argue that "context collapse" is not merely a new concept introduced by Facebook to justify its current dilemma, but has existed in popular parlance since 2008. We further learned that other social-cultural factors contributed to Facebook's "context collapse," such as the decline of traditional anthropological kinship relationships of family and close friends; rapid acceleration of online (and often anonymous) virtual relationships; and exacerbated privacy and security concerns regarding social media platforms.
\end{abstract}

Keywords: Context Collapse, Facebook, Social Media, Privacy, Trust, Naïveté, Skepticism

\section{INTRODUCTION}

In the Spring of 2016, Facebook announced that the construct of "context collapse" was the cause of a decline in people sharing original, personal content, the fuel that helps power the money machine at the heart of its social network (Frier, 2016). According to Facebook (Sunstein, 2016), overall sharing remains strong; however, as users' lists of "friends" grows exponentially, people are less willing to post updates about their lives. Staffers have reported to Bloomberg that its 1.6 billion users (Statista, 2016) are frequently posting news and information from other websites, aware that their intimate sharing of personal details may not be relevant to all their new connections. As Facebook ages, users may have more than a decade's worth of acquaintances added as "friends;" therefore, personal sharing has shifted to smaller audiences on Snapchat, Facebook's Instagram, and other messaging services. In 2016, Facebook recognized its need to re-inspire personal sharing and tried several tactics to encourage more of these posts, such as an "On This Day" feature that brings up memories that users might want to talk about again, reminders about special occasions, prompts to post photos from smartphones, e-commerce shopping, events tabs, Uber/Lyft integration, emoticon changes to the "Like" button, a live video tool, and various apps to attract chats (Dougherty, 2015). Nevertheless, The Information (Efrati, 2016) reported that Facebook's original sharing of personal stories dropped 21 percent since mid-2015.

The purpose of this paper is to explore the construct of "context collapse," its historical underpinnings, and its current influence and application to social media. Through the interpretation and analysis of pre-existing literature, we hypothesize that "context analysis" is not merely a new concept introduced by Facebook to justify its current dilemma, but is a construct popularly attributed to cultural anthropologist, Michael Wesch during a lecture at Kansas State University in 2008 and a subsequent YouTube post (Wesch, 2009). Generally, "context collapse" is a concept proffered by academics writing about the effects of social media. It refers to the infinite audience possible online as opposed to the limited groups a person normally interacts with face-to-face.

We further focus our study on the social-cultural issues that drive users to accept virtual realities and digital tools of social media as their primary sources of communication. Our literature review examined other factors that contribute to the construct of "context collapse," such as the decline of traditional anthropological kinship relationships of family, friends, and close connections; and compared them to the twenty-first century online (and often anonymous) virtual relationships directly relating to issues of trust, privacy, naïveté, and skepticism. Sociologists, 
anthropologists, social psychologists, and other subject matter experts argue that technology environments encourage avid participation into a virtual world completely reliant and trusting of the digital information received, with little or no challenge to its currency, accuracy, or completeness. Shirky (2008) pointed out that revolution does not happen when society adopts new technologies but rather through the adoption of new behaviors. Therefore, this research also explored the reasons why adults, with at least ten years of Facebook experience, have shifted their reliance and trust in sharing personal information on social media to posting and forwarding more generalized information (including re-tweeting and re-posting) to a wider augmented circle of "friends."

\section{Problem Statement}

"Context Collapse" has been identified as the rationale behind the decline of personal sharing of information and intimate details on social media platforms, such as Facebook. We hypothesize that other elements also contribute to this decline, such as fear of loss of privacy, distrust of software security applications, and skepticism that social media platforms disclose the truth their systems' compliance. For the past decade adults have trusted online communities by connecting with family, friends, and colleagues, and further establishing new relationships that are distant and further out of their core kinship groups with regard to social media and related sites. Has this early "blind" trust or naïveté in social media been replaced by skepticism, distrust, and privacy concerns further contributing to the phenomenon of "context collapse?"

\section{The Study}

Our study was a qualitative and interpretative approach to inquiry based upon a review of current online journalism articles and reports; secondary analysis of academic literature; and interviews with adult professional users of social media whom began their participation in Facebook from its early onset (2004-2006). Our motivations for undertaking this study were noted gaps in the literature regarding social media "context collapse" in concert with the influences of skepticism, distrust of security software, diminishing trust in the platform providers, and increased privacy concerns. Our interest was in determining the rationale behind "context collapse" which we believed involved more issues than an exponential widening of original sharing circles of "friends" and "likes." We then analyzed and interpreted our results to further refine our findings and develop future recommendations.

\section{LITERATURE REVIEW}

This section follows the progression of "context collapse" from a philosophical theory through its current Facebook interpretation. We then frame the constructs of "context collapse," trust, naïveté, skepticism, trolling, and privacy loss concerns as they directly relate to users strongly encouraged to participate on social media.

\section{"Context Collapse"}

From a philosophical point of view, "context collapse" is considered seminally related to Baudrillard's (1981) concept of hyper-reality and simulation resulting in the collapse of the real and the unreal, a construct he related to society's mass media communication and the influences of McLuhan and Lapham (1994). "We live in a world where there is more and more information, and less and less meaning" (1981, p. 6). Mead (1934) also argued how we understand ourselves in relation to a "generalized generalized other," foreboding our deep and profound but sometimes loose and even anonymous social connections.

boyd's (2002) MIT Media Lab Master's Thesis described "collapsed contexts" although she continues to assert that her interpretation was focused on the fear of social embarrassment regarding self-identity and approval in socialcultural situations. However, a later writing re-affirmed Wesch's view of "context collapse" with this paraphrased statement: "Social media technologies collapse multiple audiences into single contexts, making it difficult for people to use the same techniques online that they do to handle multiplicity in face-to-face conversation" (Marwick \& boyd, 2011, para. 3). boyd further asserted that Meyrowitz (1985) influenced "context collapse" with his theory of electronic media on social information systems; proffering that his holistic approach was based upon behavior and social performance and often cited no sense of place for those within the system. 
Welsch (2008, para. 4) remains the individual most generally attributed to coining the term "context collapse." Wesch [43, para. 4] described "context collapse" as an infinite number of contexts collapsing upon one another into "that single moment of a YouTube recording. The little glass lens becomes the gateway to a black hole sucking all of time and space - virtually all possible contexts - in upon itself." The term refers to massive online audiences as opposed to limited groups we normally interact with face-to-face. In those bounded interactions, people adjust their tone and presentation to fit social context; but in "context collapse," this adjusting becomes impossible. Wesch further likens his YouTube analogy to Goffman's presentation of self in social-cultural situations.

According to Goffman (1959), individuals engage in differentiated self-presentations based upon their audience. These differences may be especially prominent when comparing an individual's performance in a professional setting versus a more social one, such as Facebook. In face-to-face communication, events carefully assess the context of the interaction in order to decide how we will act, what we will say, and how we might try to construct and present ourselves. Goffman argued that continuously and unconsciously we take note of the physical surroundings, the people present, and the overall tone and temper of the scene, among other things. When engaged in social interaction, a person is not only evaluating the situation, but also his own self and how one fits into the situation. In Goffman's (1967, p. 5) terms, one must develop a "line" presenting his version of the situation, others, and his own self. The image he portrays of himself (his "face") is constantly being negotiated, a process Goffman calls "face-work" (p. 12). Face is not simply defined by the person's actions, but how those actions are perceived and judged by other participants in the flow of the encounter. How we present ourselves depends a great deal upon context, where we are, who we are with, and what we are doing, among many other factors.

When engaged in social interactions during face-to-face or group scenarios, we evaluate situations and people as well as ourselves, and how we fit into these scenarios. These are necessary to engage in conversation and to be social. However, in social media, face-work does not have the same value because we don't see the expressions of those with whom we are communicating. This online phenomenon is expressed as "context collapse," because all of those visuals, interpretations, and calculations used to evaluate situations are gone, removed, and collapsed within social media interaction.

\section{Anthropological Underpinnings and Kinship Relationships}

To illustrate the decline of social media relationships over the past decade from familial kinships to varying degrees of colleagues, acquaintances, and the acceptance of anonymous "friends," we included three figures from our seminal social media research related to online blind trust, privacy, naïveté, and skepticism (Borkovich \& BreeseVitelli, 2014).

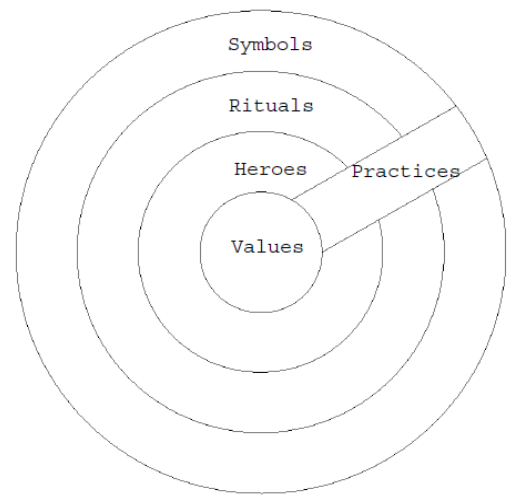

Figure 1. Depiction of "The Onion," Manifestations of Culture at Different Levels of Depth (c. Hofstede, Hofstede, \& Minkov, 2010, p. 8)

As depicted in Figure 1, Hofstede, Hofstede, and Minkov (2010) clearly identified the kinship groups of familial "trusted" relationships illustrated as the core values, ethics, and morals as concentric layers of an onion. The outer layers, expressed as practices, exemplify lesser degrees of reliance upon friends, classmates, organizational 
members, work colleagues, and society in general. However, value systems and learned shared practices shape the core of our social-cultural mores as we learn whom we can trust for our survival and well-being, and whom we cannot. This depiction represents users indoctrination to social media (Facebook, 2004-2006) when groups were small and intimate and information sharing was limited to well-known persons in a restricted circle of "friends."

Palfrey and Gasser (2008) advanced the metaphoric "onion" into the $21^{\text {st }}$ century by depicting the Digital Native (Prensky, 2001; Dent, 2008; Selwyn, 2009) at its core, and not the traditional familial values of Hofstede (1980). Figure 2 illustrates the Digital Native's trusted relationships beginning with friends and family; teachers, coaches, and mentors; trusted companies and software providers; and at its outermost layer, law enforcement. The Digital Native Onion is focused on the online and virtual familial guidance provided by friends and family; teachers, coaches, and mentors for online navigation training; trusted companies and software providers for technology products and services; and law enforcement as a security instrument accessed and used only as a last resort (Palfrey \& Gasser, 2008). Note that "context collapse" has begun to draw social media users, Digital Natives and Immigrants (Prensky, 2001) alike, away from familial kinship groups to lesser known acquaintances.

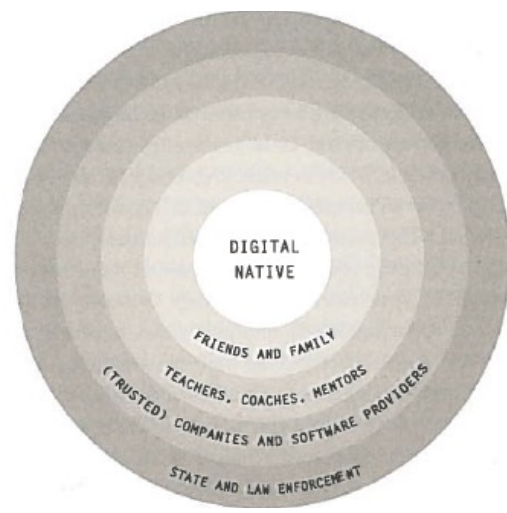

Figure 2. Depiction of the "Onion" Through the Lens of the Digital Native (c. Palfrey \& Gasser, 2008, p. 11) Shows the Social Media Circle of "Friends" Enlarged from the Original Kinship Group to Lesser-Known Outsiders

Turkle (2011, p. 1) suggested that "technology is seductive when what it offers meets our human vulnerabilities. ... Digital connections offer the illusion of companionship without the demands of friendship. Our networked life allows us to hide from each other, even as we are tethered to each other." She further argued that when technology engineers intimacy, relationships are reduced to mere connections, and connections are redefined as intimacy. Turkle (p. 153) asserted that virtual places offer connections and a sense of community without claims to commitment: "We don't count on cyberfriends to come by if we are ill, to celebrate our children's successes, or help us mourn the death of our parents." Turkle's (p. 295) narrative provides this summary: "We expect more from technology and less from each other....We would rather text than talk." 


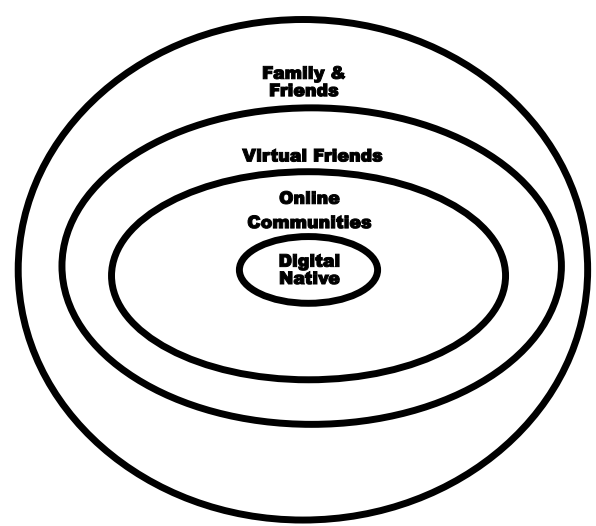

Figure 3. Depiction of the "Virtual $21^{\text {st }}$ Century Onion" (c. Borkovich \& Breese-Vitelli, 2014, p. 403). Forecasting the onset of "context collapse," the Digital Native prefers online communities, then virtual friends, and lastly family and friends (in the outermost position) by reversing and displacing the traditional and trusted core familial anthropological relationships with distant and often anonymous online contacts.

As illustrated in Figure 3, following a decade of social media participation, networks of "friends" become exponentially large, unwieldy, and to some extent anonymous. "When you change the contents of your circle, you change your conception of yourself. The center of the circle shifts as its perimeter is changed. The liberal impulse is to expand the circle, while conservatives tend to want to restrain or even contract the circle" (Carr, 2011, p. 37).

Web 2.0 has taken the world into a virtual reality where ubiquitous internet participation is advocated and welcomed. Information is streaming live at break-neck speed with little regulation or oversight, and a vast opportunity exists to post subjective opinions in lieu of objective information. Postman (1993, p. 70) described "information appear[ing] indiscriminately, directed at no one in particular, in enormous volume and at high speeds, disconnected from theory, meaning, or purpose." Social media sites are no less aggressive and volatile, aware that users are high-energy, fast-paced, rapid-response earners, consumers, and information producers.

\section{Social Media Culture}

A culture based upon openness, trust, respect, collaboration, shared meanings, and resources reflects a mutual understanding of goals, objectives and purpose, but how are these values and mission applied to "group-think" in a virtual environment of loose connections? Technology and culture tend to evoke dramatically different connotations, systems of meaning, experiences, and worldviews (Bateau, 2010). As naïve as this statement may be, some believe there are no problems that cannot be solved without some form of technology. Technophiles (Postman, 1993) and early adopters $[9 ; 10]$ argue that technology represents a necessary upheaval, innovation, and creative destruction to the permanence and stability of organizational, societal, and national culture. The socio-technical theory (Bostrom \& Heinen, 1977) describes the interaction between people and technology in the workplace and social informatics (Kling, 1999) provides the tools of the interface.

Trust. Within human communities, trust is a common construct based upon familial values and a shared topology of stable relationships and identities. We automatically trust those with whom we feel some shared connection, even when we meet them for the first time. This kinship can be based on family, ethnicity, nationality, profession, education, religion, employment, or a number of other shared characteristics. Batteau (2010) argued that societies are made up of complex webs of trust, mistrust, and disinformation among groups, individuals, and institutions learned over years of interaction. Rainie and Wellman (2010) pointed out that trust and reciprocity are primary currencies on social media when working toward building social capital in digital formats.

Naïveté. As humans mature we still tend to fuse seeing with believing. Philosophers call this view naïve realism (Ross \& Ward, 1996), that we see reality as it really is, objectively and without bias. We also tend to believe we have full command of the facts and the patterns, and that everyone else agrees with us (Pariser, 2011). When our 
social life is miserable, depressing, or oppressive, escapism is a reasonable response. And if we feel lonely or abandoned, it is probably not far-fetched or coincidental that technology is alluring and convenient. Although technology doesn't solve every problem of its own accord, Pariser (p. 187) argued that: "Technodeterminists like to suggest that technology is inherently good."

Skepticism. Postman (1993) coined the term, Technopoly, with its emphasis on progress without limits, rights without responsibilities, and technology without cost. "Technopoly is without a moral center" (Postman, p. 179) and places efficiency, convenience, interest, and economic advance through technological progress. Postman asserted that this feature of the American ethos is plain to everyone who has studied American culture. Postman (p. 53) further argued that: "It is enough to say that the American distrust of constraints - one might even say the American skepticism toward culture itself - offered encouragement to radical and thoughtless technological intrusions."

Privacy and Trolling. According to Lanier (2010, p. 60): "Troll is a term for an anonymous person who is abusive in an online environment." And anyone who is a Blogger, Friender, Liker, or Twitterer can attest to this unpleasant phenomenon and subsequent loss of privacy. Facebook and Instagram users notoriously create successful online fictions about themselves, albeit doppelgängers; however trusting naïve members of online communities may not realize the false connections they are making. And personalized online introductions that are techno-pushed by Web 2.0 tend to filter and classify people into bubbles, once again pushing narrow-casted content so that one tends to continually meet like-minded individuals, at times for nefarious purposes.

This literature review argued that many subject matter experts were adamant that individuals were more than willing to abandon the safety and security of family, close friends, and reliable inner circles as trusted online sources; easily displacing them for online communities, anonymous "friends," and other invisible news curators. Americans were prepared to accept anonymous online communities, to communicate with strangers, and to share and receive private information under the cloak of anonymity. However, this trend diminished over a period of ten years when the online communities (circles of "friends") became so large and unwieldy that one cannot satisfy all the interests of the online society; resulting in users' willingness to abandon their original premise to share personal information in favor of posting generalized news, links to other sites, and re-forwarded tweets.

\section{INTERVIEWS}

Twenty-two professionally employed adult Facebook users, whom experienced a decade of online experience, were interviewed by soliciting their opinions of social media related to "context collapse," privacy, security, trust, naïveté, and skepticism. Table 1 depicts the participants' demographics followed by a limited selection of summarized comments from five unstructured interviews.

\begin{tabular}{|c|c|c|c|c|c|c|c|c|}
\hline \multicolumn{8}{|c|}{ Table 1. Adult Facebook Users' Demographics } \\
\hline $\begin{array}{c}\text { Adult } \\
\text { Interviewees }\end{array}$ & $\begin{array}{c}\mathbf{1 0} \text { Yrs. } \\
\text { Experience on } \\
\text { Facebook }\end{array}$ & $\begin{array}{c}\text { Ages } \\
\mathbf{3 0 - 4 0}\end{array}$ & $\begin{array}{c}\text { Ages } \\
\mathbf{4 1 - 6 5}\end{array}$ & $\begin{array}{c}\text { Frequent } \\
\text { Users }\end{array}$ & $\begin{array}{c}\text { Sometimes } \\
\text { Users }\end{array}$ & $\begin{array}{c}\text { Rare } \\
\text { Users }\end{array}$ & $\begin{array}{c}\text { Stopped } \\
\text { Posting }\end{array}$ & $\begin{array}{c}\text { Currently Post *Personal; } \\
* * \text { Non-Personal; or } \\
* * * \text { Both Types of Info }\end{array}$ \\
\hline $9(41 \%)$ & Males (Mx) & 3 & 6 & 2 & 2 & 3 & 2 & $\begin{array}{c}* * \text { Non-Personal or } \\
\text { No Longer Post }(41 \%)\end{array}$ \\
\hline $13(59 \%)$ & Females (Fx) & 4 & 9 & 10 & 2 & 1 & 0 & Post ***Both $(59 \%)$ \\
\hline $\mathbf{2 2 ~ ( 1 0 0 \% )}$ & Totals & $\mathbf{7}(31 \%)$ & $\mathbf{1 5}(69 \%)$ & $\mathbf{1 2}(55 \%)$ & $\mathbf{4}(18 \%)$ & $\mathbf{4}(18 \%)$ & $\mathbf{2}(9 \%)$ & $\mathbf{1 0 0 \%}$ \\
\hline$*$ Personal info defined as: Family, extended family, close friends, parties, shopping, children, hobbies, vacations, home, pet info and photos. \\
\hline$* *$ Non-Personal info defined as: News, sports, clubs, teams, politics, resumes, job-hunting, e-commerce, re-tweets, etc. \\
\hline
\end{tabular}

F3 (41-65 Age Group): "I started posting on Facebook years ago and really enjoyed staying in touch with my relatives and kids in college. I even got to the point where I stopped writing letters and thank you notes and started to post all the information on my Facebook page. But now I have so many "friends" --- some I don't really know all that well --- and they really aren't interested in my photos and news. So now I text my kids and send photos to my relatives from my phone. I'm just not on Facebook as much as I used to be." 
M5 (30-40 Age Group): “When Facebook first appeared on the scene, I couldn't wait to get online. I used it to keep in touch with guys from my softball team and I'm embarrassed to admit it - but I also wanted to meet girls with similar interests. This was years ago before I got married. Now I lost interest because I don't really have the time to keep up with all the "friends" I acquired over the years and I don't really feel the need to tell everybody everything about me anymore. And I leave Facebook updates to my wife when she has the time."

F6: (30-40 Age Group): "I still like Facebook, but I get more social interaction from Snapchat and Twitter. I prefer texting to emailing, too, so I spend most of my time on my smartphone. I have more control when I text. I can be sure that I know who I am sending my info to, and I only send the info I want them to know."

M7 (41-65 Age Group): "Over the past couple of years I have pretty much abandoned Facebook and other social media. My smartphone has taken its place for everything I want to share. And I don't have to worry about who I am sharing with or what the next person is doing with my information. I am really worried about all the hackers and data breaches and my wife still posts too much information about where we are going and where we've been. I can't even tell you all the times I uploaded my social security number online to a 'secure' website or made a purchase with my credit card. I am worried all the time about identity theft and starting to distance myself from social media interaction except when it is required. It's not fun anymore and keeping up with all the "friends" is too much work!"

M9 (41-65 Age Group): "I have a security clearance at work and I want to work another 10 years before I retire. I just read that Government agencies are checking posts on all popular social media sites for suspicious activity and will pull clearances if a post doesn't look or smell right. I can't take that kind of chance so I am off social media until I retire. And since Facebook can't protect me from the Feds or save my job, I'm not using it anymore."

\section{INTERPRETATION}

From our secondary analysis of social media literature and interviews with adult posters, we learned that Facebook users can become "friends" with members from a variety of contexts (family, friends, classmates, coworkers, neighbors, etc.); and all of these "friends" are grouped together on a single large general purpose site (Sibona, 2014). "The lack of spatial, social, and temporal boundaries makes it difficult to maintain distinct social contexts" (boyd, 2014, p. 41] and the specific topics can no longer be effectively communicated and directed to all participants. Connections on social network sites are formed under a variety of contexts, ranging from maintaining existing relationships and creating new ones, forming romantic connections, and job-searching (Palfrey \& Gasser, 2008). Online friendships are fluid and easily dissolved on social network sites where a connection can be erased with one click. Pew (Madden \& Smith, 2012) reported that $63 \%$ of users unfriended at least one member of their online social network in 2011 up from 56\% in 2010. Facebook unfriending is a widely-used feature that may become instrumental as a mitigation device or escape route from "context collapse."

"Context collapse" occurs in online social networks because a variety of friends from different contexts are grouped together in a single location. Similar to boyd (2010), Hampton, et al. (2011), Marwick and boyd (2011), and Vitak, et al. (2012), our results evidenced that adult users navigated online spaces through invisible audiences, collapsed context, and the blurring of public and private boundaries. Our interviewees developed their own strategies to manage "context collapse," such as not accepting friend requests from work-related acquaintances on their personal accounts, creating multiple Facebook accounts for professional activities and personal contacts, and avoiding controversial topics and massive audiences by dropping Facebook. Several of our interviewees remarked that they enjoyed Twitter more than Facebook due to the broad appeal of the ability to forward or re-tweet more generalized anonymous content. Twitter's audience is difficult to determine, because under the default privacy options, tweets are publicly accessible, but followers may not be. We found that Digital Natives and Immigrants alike are in the midst of a paradigm shift from previously trusted social media sites comprised of kinship "friends" to a wider socialcultural society of users that can no longer be completely controlled or similarly engaged.

We realize audiences still enjoy accessing social media and vast free online information abounds, but what people trust has bright and dark moments. Misinformation and propaganda have always been central to both sides of social movements. While technology is neutral, people are not (Schmidt \& Cohen, 2013). Connectivity can and will help 
upend power imbalances, expose corrupt officials, and other malevolent forces including where freedom of the press is limited or non-existent. However, our research also evidenced that the darker side of social media participation, such as directed personalization, narrow-casting, echo chambers, and trolling, have the ability to narrow one's focus, distort perceptions, and influence one's worldview by controlling and limiting the push content to the agendas of online bloggers, vloggers, and news curators funded or backed by their respective advertisers, sponsors, lobbyists, and political activists. Our findings suggest that continued social media trust and naïveté, without second vetting and sourcing of participants ("friends") and control of audience size, will continue to manifest itself in trends toward online conditions that will perpetuate "context collapse."

Turkle (2011, p. 295) argued that when we are overwhelmed by an influx of data, "we expect more from technology and less from each other," drawing us to digital media solutions that are convenient, responsive, and speedy. Sometimes the only online feedback we hear merely echoes our own preconceived beliefs (Pariser, 2011). Our research evidenced that exponential communities of users on a single site will result in the same overwhelming echo effect. A potential remedy to "context collapse" may be the filtering and rebranding of "friends" into various categories of access, participation, sharing, and intimacy. Pariser (2011) asserted that pushed personalization and customized access permits the user to bask in a comfort zone, without the distractions of other opinions, worldviews, and conflicting positions. Today's Digital Natives and Immigrants need to strike a balance between the perceived comfort and safety of directed customized content and the distracting information overload (Borkovich, 2012) of infinite participants and search possibilities. Is there still doubt that "context collapse" exists?

\section{LIMITATIONS AND FUTURE APPLICATIONS}

Our unstructured interviews, comprised of only 22 adult respondents with ten years of Facebook experience, requires a much larger sample size to generate hard validity and transferability of the results. Nevertheless, on a very small scale, we confirmed the theories of several subject matter experts that "content collapse" exists; but further discovered that other factors influenced Facebook users' decline in sharing personal information to extended networks of "friends." Our results affirmed that increased concern about lack of privacy, loss of security regarding personal information, and increased distrust of social media platforms contributed to the phenomenon of "context collapse." From our limited study, we deduced that some adults are no longer willing to sacrifice trust, privacy, reliability, and credibility for short-term, often anonymous sources that a single communicator cannot possibly placate equally on social media.

As the lines continue to blur between professional and private lives on social media, trust in personal brands and products, software applications and compliant media platforms will be paramount. Our future research will explore the idea of hacker culture personal branding to determine the impact it may have to portray the average anonymous citizen as a subject matter expert on social media platforms. Although our current research addressed the elements that influence "context collapse," additional questioning of naïveté and skepticism in addition to blind trust, privacy and security concerns will provide further insight into how and why traditional anthropological kinship relationships are radically changing into preferred virtual relationships.

We propose larger-scale qualitative and quantitative studies be pursued, and encourage exploration of additional online software platforms to surface additional clues regarding the social media implosion of "context collapse." We further purport that "context collapse" does not solely apply to Facebook and should be explored among different online venues and social-cultural environments to compare and contrast our findings with other social media.

\section{CONCLUSION}

In the Digital Age, relationships are mediated by social media; therefore social media has the ability to change, enhance, and augment these relationships. We negotiate our identities through our control of relationships with others; however, this control is inhibited by communicating with large, unwieldy, and often unrelated groups of "friends" and acquaintances on social media. This lack of control of our exponential online relationships has led to "context collapse," a social media implosion, resulting in fear, loss of privacy and control of our shared information. 
This has led to skepticism and distrust of the system(s), and increased personal accountability for our posts, in lieu of our prior expectations for a reasonable amount of privacy, protection, and security from social media platforms.

Media changes, updates, new versions, enhancements, apps, etc. will always alter our relationships with others on social media. And they will continue to affect how we create and re-create our identities. We must be prepared for the continued phenomenon of "context collapse" as new media spaces encourage a vast networked social-cultural environment where information is difficult to maintain, albeit, in some cases impossible, without further understanding of the tools we use. We require and should demand enhanced privacy and security protocols from the social media platforms that rely upon our participation for their funding and existence. We proffer that when personally shared information within interrelated and unrelated groups overlap, interface, and converge upon each other, the lines of communication, understanding, and meaning blur and deteriorate. To survive and thrive, social media providers need to understand the changing sharing motivations of their users, or their "contexts" will continue to collapse and implode from their weight.

\section{REFERENCES}

Batteau, A. W. (2010). Technology and culture. Long Grove, IL: Waveland Press, Inc.

Baudrillard, J. (1981). Simulacres et Simulation (S. Glaser, Trans.). Ann Arbor, MI: University of Michigan Press. [Original work published 1978]

Borkovich, D. J. (2012). When corporations collide: Information overload. Issues in Information Systems, 13(2), 269-284.

Borkovich, D. J., \& Breese-Vitelli, J. (2014). The influence of mobile technology culture: Blind trust, naïveté, or skepticism. Issues in Information Systems, 15(2), 399-410.

Bostrom, R. P., \& Heinen, J. S. (1977). MIS problems and failures: A sociotechnical perspective - Part I: The cause. MIS Quarterly, l(3), 1977, 17-32.

boyd, d. (2002). Faceted Id/entity: Managing identity in a digital world. MIT Media Lab. Retrieved from: http://www.danah.org/papers/Thesis.FacetedIdentity.pdf

boyd, d. (2010). Social network sites as networked publics: affordances, dynamics, and implications. $A$ networked self: Identity, community, and culture on social network sites. New York: Routledge.

boyd, d. (2014). It's Complicated: The Social Lives of Networked Teens. New Haven: Yale University Press.

Carr, N. G. (2003). IT doesn’t matter. Harvard Business Review OnPoint, 3566, 41-49.

Carr, N. G. (2004). Does IT matter? Information technology and the corrosion of competitive advantage. Boston, MA: Harvard Business School Press.

Carr, N. G. (2011). The shallows: What the internet is doing to our brains. New York, NY: W. W. Norton \& Co.

Dent, A. (2008). Are you a digital native? If you are over 22, you're an immigrant. Birmingham Post UK, 1(20).

Dougherty, J. (2015, December 21). 10 New Facebook features for 2016. Cision Online Publication. Retrieved from: http://www.cision.com/us/2015/12/10-new-facebook-features-for-2016/

Efrati, A. (2016, April 7). Facebook Struggles to Stop Decline in 'Original' Sharing. The Information Online. Retrieved from: https://www.theinformation.com/facebook-struggles-to-stop-decline-in-original-sharing 
Frier, S. (2016, April 7). Facebook wants you to post more about yourself. Bloomberg Online Publication. Retrieved from: http://www.bloomberg.com/news/articles/2016-04-07/facebook-said-to-face-decline-in-peopleposting-personal-content

Goffman, E. (1959). The presentation of self in everyday life. New York: Anchor Books.

Goffman, E. (1967). Interaction ritual: Essays on face-to-face behavior. New York: Anchor Books.

Hampton, K., Sessions, L., Rainie, L., \& Purcell, K. (2011). Social networking sites and our lives. Pew Internet \& American Life Project. Retrieved from: http://www.pewinternet.org/2011/06/16/social-networking-sites-andour-lives/

Hofstede, G. (1980). Culture's consequences: International differences in work-related values. Beverly Hills, CA: SAGE Publications, Inc.

Hofstede, G., Hofstede, G. J., \& Minkov, M. (2010). Cultures and organizations: Software of the mind. New York: McGraw-Hill.

Kling, R. (1999). What is social informatics and why does it matter? D-Lib Magazine, 5(1). Retrieved from: http://www.dlib.org/dlib/january99/kling/01notes.html

Lanier, J. (2010). You are not a gadget: A manifesto. New York: Alfred A. Knopf, Division of Random House.

Madden, M., \& Smith, A. (2012). Privacy management on social media sites. Pew Internet \& American Life Project Report, February 24, 2012. Retrieved from: http://www.pewinternet.org/2012/02/24/privacymanagement-on-social-media-sites/

Marwick, A., \& boyd, d. (2011). I tweet honestly, I tweet passionately: Twitter users, context collapse, and the imagined audience. New Media Society, 13, 114-133.

McLuhan, M., \& Lapham, L. H. (1994). Understanding media: The extensions of man. Cambridge, MA: MIT Press, Inc. (Originally published 1964)

Mead, G. H. (1934). Mind, self and society. Chicago: University of Chicago Press.

Meyrowitz, J. (1985). No sense of place: The impact of electronic media on social behavior. New York: Oxford University Press.

Palfrey, J., \& Gasser, U. (2008). Born digital: Understanding the first generation of digital natives. New York, Basic Books.

Pariser, E. (2011). The filter bubble: How the new personalized web is changing what we read and how we think. New York: Penguin Books.

Postman, N. (1993). Technopoly: The surrender of culture to technology. New York: Vintage Books.

Prensky, M. (2001). Digital natives, digital immigrants. On the Horizon, 9(5), 1-6. Retrieved from: http://www.marcprensky.com/writing/prensky

Rainie, H., \& Wellman, B. (2012). Networked: The new social operating system. Cambridge, Mass: MIT Press.

Ross, L., \& Ward, A. (1996). Naive realism in everyday life: Implications for social conflict and misunderstanding. In T. Brown, E. S. Reed, \& E. Turiel (Eds.), Values and Knowledge (pp. 103-135). Hillsdale, NJ: Erlbaum. 
Schmidt, E., \& Cohen, J. (2013). The new digital age: Reshaping the future of people, nations, and businesses. New York: Random House.

Selwyn, N. (2009). The digital native - myth and reality. Aslib Proceedings: New Information Perspectives, 61(4), 364-379.

Shirky, C. (2008). Here comes everybody: The power of organizing without organizations. New York: Penguin.

Sibona, C. (2014). Unfriending on Facebook: Context collapse and unfriending behaviors. In 2014 47th Hawaii International Conference on System Science Proceedings, Waikoloa, HI, pp. 1676-1685. Retrieved from: $\mathrm{http}: / /$ ieeexplore.ieee.org/stamp/stamp.jsp?tp=\&arnumber=6758811\&isnumber=6758592

Statista Online. (2016). Number of monthly active Facebook users worldwide as of 1st quarter 2016 (in millions). Statista - The Statistics Portal. Retrieved from: http://www.statista.com/statistics/264810/number-ofmonthly-active-facebook-users-worldwide/

Sunstein, C. (2016, January 8). How Facebook makes us dumber. Bloomberg Online Social Media View. Retrieved from: http://www.bloomberg.com/view/articles/2016-01-08/how-facebook-makes-us-dumber

Turkle, S. (2011). Alone together: Why we expect more from technology and less from each other. New York: Basic Books.

Vitak, J. (2012). The impact of context collapse and privacy on social network site disclosures. J. Broadcast Electronic Media, 56, 451-470.

Vitak, J., Lampe, C., Gray, R., \& Ellison, N. (2012). Why won't you be my Facebook friend? Strategies for managing context collapse in the workplace. In iConference'12 Proceedings, February 7-10, 2012, Toronto, Ontario, Canada. [This work was supported by NSF grant IIS-HCC-0916019.]

Wesch, M. (2008, July 31). Context collapse. Digital Ethnography at Kansas State University. Retrieved from: http://mediatedcultures.net/youtube/context-collapse/

Wesch, M. (2009). YouTube and you: Experiences of self-awareness in the context collapse of the recording webcam. Explorations of Media Ecology, 8(2), 19-34. 